\title{
Service User Involvement in an Undergraduate Nursing Programme
}

\begin{tabular}{|r|l|}
\hline Journal: & Journal of Mental Health Training, Education and Practice \\
\hline Manuscript ID & JMHTEP-12-2018-0073.R2 \\
\hline Manuscript Type: & Case Study \\
\hline Keywords: & Mental Health Education, Service User Involvement, Nurse Education \\
\hline \multicolumn{2}{|l}{} \\
\hline
\end{tabular}




\title{
Service User Involvement in an Undergraduate Nursing Programme
}

\begin{abstract}
This article highlights the significant-impacts that service user involvement had-can have on the education of UK undergraduate student mental health nurses both personally and professionally. It reports the findings from a short service module evaluation of a collaboratively delivered theory unit using a qualitative approach.

-embracing two focus groups.

The findings from the two focus groups highlight that the service user input ('expert by experience') offered a positive learning experience for the students, enabled them to appreciate the meaning of a-recovery and hope, facilitated the identification as to the importance of their role in terms of connecting meaningfully with elients those they are supporting plus reconsidering key priorities for practice. They suggest also that there is theory/practice gap reduction as students were able to connect the service user narratives to the evidence base for deeper understanding and application.

Although only a brief evaluation of a short theory unit within a wider mental health programme including a limited number of students, the findings echo the wider literature and offer further rationale to support direct service user involvement in mental health education across other professions, perhaps interesting at this time as increasingly, learning/teaching programmes implement blended learning with significant online teaching and less face to face facilitation of learning.

Although-Tthere is much in the literature as to the benefits for student learning in involving service users within HEI education, however there remainsis limited information as to 'how' and 'why' this is the case, this article seeks to bridge that gap.
\end{abstract}

\section{Key Words}

Mental Health Education, Service User Involvement, Nurse Education,

This article is a case study describing the findings of a brief service-module evaluation of a delivered taught unit as part of an undergraduate teaching programme which sought to meaningfully involved service users as part of the collaborative delivery.

\section{Background}

"Wherever you find humans, you will also find stories" (Cobley., P. 2001 cited in Holloway and Freshwater 2007 p.703)

An undergraduate Mental Health Nursing Programme (BSc Hons) at a Higher Education Institute (HEI) in the South of England (UK) leads to professional registration with the UK Nursing and Midwifery Council (NMC) and currently delivers six assessed units per academic year over the three year programme, each unit in alignment with, and reflective of, the students' 
concurrent learning experience in practice. Prior to the most recent curriculum rewrite in 2018, the third year of the programme required the students to undertake a six day unit focussing on caring for those with severe and enduring mental health issues.- the -The core aim of this unit to facilitate enable the students in the development of adevelopingto develop a critical understanding pertaining toof the relevant current evidence based therapeutic approaches. The teaching team for this unit included a Mental Health Lecturer Practitioner (LP) alongside three Experts by Experience /Service Users (SU), plus a Mental Health Lecturer/Researcher (L)._All stakeholders contributed to the development and teaching for the unit, with SUs comfortable with their role being (self) described as SUs, patients, clients or experts by experience depending on their individual preference and common usage within the programmee.

As within all Higher Education Institutions (HEI) in the UK, student evaluation and feedback of the teaching units is a core dimension of the ongoing quality monitoring systems in place at the university. For this particular unit in the past, student feedback was sought after each day, and it became very evident to the teaching team that, that the most enthusiastic and positive feedback followed those sessions delivered by the SUs, as ene narrative sessions delivered on each of the 6 teaching days, usually lasting between one or two hours to allow for interactive questions and feedback. As part of the teaching team, the SUs chose to use storytelling, sharing their experiences of mental health services and mental ill-health/distress, within the sessions. The SUs were experienced facilitators of learning and chose the content, style and delivery of the stories, their aim to bring a 'humanistic' perspective to care in sharing their personal experiences (Grant et al 2012, Bocking et al, 2019)). Commonly the themes of the narratives highlighted the importance of interpersonal skills and communication/use of language and also the prevailing ehallenges for service users regarding treatment options (including coercion and availability of responsive services) plusand stigma surrounding diagnoses (Bocking et al 2019) alongside including appreciation and application of the Recovery approach approaches to Recovery.

A team brief review of all prior formative and summative feedback suggested that the SU sessions offered the students a 'different and deeper' learning experience as described by the students compared to facilitated learning by professionals and academics, but there was little articulation as to what was meant by this. 
Mindful as to the plethora of robust evidence confirming SU input into educational courses for health and social care professionals as a positive pedagogical strategy_(Happell and Bennetts 2016, Arblaster et al. 2015; Happell et al. 2014, Blackhall, 2012), the teaching team were not surprised as to this finding, however, there was an agreed case for further exploration-as to what students meant by ' a different and deeper learning experience'. Furthermore, having briefly reviewed the current evidence base, the team felt there was a specific need to try and-identify further-why SU input was significant in this unit for learning, and-plus also what impact this learning may have upon students for both their academic and professional development and practice.

_, especially since in $\underline{I n}$ the UK it is mandatory to include SUs within_the-healthcare curriculaum (NMC, 2010, HCPC, 2013), Department of Health 2012; Rhodes, 2012, Frances 2013, NHS 2015). 9 NMC, 2010.) and as advocated by the Francis Report (2013) also. Indeed, aAs Simpson et al highlight (2008), since the 1990s, service user involvement has been advocated-deemedas important for health professionals education particularly for nursing as highlighted within the Chief Nursing Officer's Review of Mental Health Nursing (DOH, 2006) thus echoing social work education which made this facet mandatory during development of the degree programmes with -Askheim et al (2017) suggested mainstreaming service user participation in all stages of healthcare education ${ }_{-}$. Since 2000 , theThe literature base has further expanded over the last decade-to suggest that, particularly for mental health education, the aims and objectives of SU involvement should-to embracincludeing sharing experiences of the recovery model/-and philosophy of mental health care incorporating and a strengths based approach to support withand empathy and careempathic care - delivery-focussed on the client not the service. More currently, the work of Horgan et al (2018) articulates that involvement of service users in education has now progressed to not only widespread within curricula but to the (limited) appointment of service user academics (Happell et al 2014). Furthermore, the ongoing inclusion efInclusions of service users in professional education hasis reported as also effective in alse positively influencing student's attitudes, pluswhilst enhancing communication skills especially throughand successfully exploring students' misconceptions about mental illness (Perry et al, 2013, (Happell et 2015). Drawing from UK social work education, as Beresford (1994) also identified, involvement of service users in education can change the culture of both workers and organisations. In the UK, Social work education has embraced service users since the 1980s and 
werewas pivotal in ensuring their inclusion into SW degree programmes from 2003 to include student recruitment, curriculum design and assessment. He also highlighted that, even then, students valued their contribution.

Given awareness of the above and previous positive feedback the team decided to undertake a different module evaluation to explore in more depth how and why the SU input was viewed so positively. Limited resources guided the project in many ways eg. Availability/access to the students within the programme, and time availability of the team with other commitments, therefore the team decided to undertake a revised module evaluation as a scholarly activity within their own time.

It should be noted that, aAs part of the teaching team, the SUs chose to use storytelling, sharing their experiences of mental health services and mental ill-health/distress, within the sessions. The SUs were experienced facilitators of learning and chose the content, style and delivery of the stories, their aim to bring a 'humanistic' perspective to care in sharing their personal experiences (Grant et al 2012, Bocking et al, 2019) and also to offer perspectives as to what the students (future workforce) could consider in shaping healthcare delivery and policies (Beresford et al, 2006). Commonly the themes of the narratives highlighted the importance of recovery approaches, interpersonal skills and communication/use of language and also the prevailing challenges for service users regarding treatment options plus-(including coercion and availability of responsive services). Also included was the effects of stigma surrounding diagnoses (Bocking et al 2019). alongside appreciation and application of approaches to recovery. Where storytelling, the expert use of narratives, is used for learning, Grant et al (2012), suggest that students benefit from an enhanced understanding of the client experience, notwithstanding the eritique that it can also be viewed as tokenistic often reflecting a power imbalance between professionals (clinical and academic) and service users (Epstein 2015). However, the involvement of service users can be perceived as also adding credibility to the curricula and the learning experience (Happell and Bennetts 2016) and as Ranjan (1992) suggests it also facilitates students to be more aware of their current practice and informs their future practice.

Where storytelling, expert use of narratives, is employed for facilitation of learning, Grant et at (2012, suggest that students benefit from an enhanced understanding of the client experience, notwithstanding the critique that it can also be viewed as tohkenistic often and reflecting a power 
imbalance between professionals (clinical and academic) and service users (Epstein 2015). The involvement of service users can be perceived as also adding credibility to the curricula and the learning experience (Happell and Bennetts 2016) and as Ranjan (1992) suggests it also facilitates to be more aware of their current practice in informs their future practice (Ranjan 1992, cited Kuti and Houghton 2019)

Given awareness of the above and previous positive feedback $t$ The team decided to undertake at deeper different service module evaluation during the time that the unit was being delivered to explore in more depth how and why the SU input was viewed so positively in the current year. Limitiedng resources guided the project in many ways eg. Availability/access to the students within the programme, time availability of staff the team with other commitments, lack of time to bid for and secure formal research/evaluation funding. The team decided to undertake $\underline{a}$ revisedthe service module evaluation as a scholarly activity within their own time with a view to developing a larger scale funded research project later in the academic year.

\section{Methods and Methodology}

The team shared an agreed (interpretative) philosophy in that reality is subjective rather than objective in terms of meaning and interpretation where the students' experience was being sought based on their 'individual reality' of learning from service users (Malterud, 2001) thus all agreed to adopt an explorative and descriptive stance rather than a positivist, predictive stance (Schneider et al, 2013). Morse (19922012) highlightsconfirms that qualitative research methodology is interpretative, explores the social world, and seeks to identify how this world is interpreted, understood, experienced and produced - in this case, from the perspective of the students.:

As a consequence, alt was agreed that to add rigour and trustworthiness to the proposed undertaking, research methodology and methods would be considered within the necessarily 
imposed time limits (duration of the unit delivery was 6 days only). The 1 qualitative (interpretative) paradigm in a humanistic tradition (Dahl et al, 2019) was deemed agreed as best suited for this endeavour as the team were seeking to explore and describe the meaning of the student experience of SU input intowithin their educations. as opposed to the quantitative (positivist) paradigm, the latter most often used in those projects seeking to quantify, generalise, and predict objectively. In For the service evaluation, in-adopting a qualitativethis approach, there would be the scope to embrace the naturalistic nature of this paradigm in that the students involved 'naturally' accept their role as engaged HEI nursing students who are regularly asked for feedback as to their learning experiences and are commonly involved in research as participants and co-researchers.

The teaching team agreed-were aware that that they findings could not were not seeking to find answers to questions that could be confidently be applied to all nursing students ie. There was no need to confirm generaliseability, rather they were seeking to build a picture of what was being studied (Hewitt Taylor 2011), in this case, specifically the impact of SU input on final year mental health nursing students' education and practice.

From the agreed paradigm which provided a consensus as to the values and beliefs of the team as to the importance of the work and the approach to be adopted, the appropriate methods and methodology were considered to ensure the necessary information (data) would be collected appropriately and in a suitable format for meaningful analysis to offer new understanding and insight.

The qualitative research designexploratory approach and approach of Stebbens (2001) was identified as the most appropriate as an approach to explore the the topies of interest by facilitating the conditions for participants to inform the topic of interest to allow the participants to reflecting $\underline{\text { offer }}$ their views, opinions and expertise on being taught by SUs, the topic broadly mindful of methodological stance for focus groups (Stewart \& Shamdasani 1990; Kitzinger 1994, cited Happell and Bennets 2016). This approach is suggested as being considered when there is limited evidence to support a particular identified methodological approach (Happell et al, 2017), in this scenario, exploring specifically how and why SU narrative input was viewed positively with a single cohort of final year undergraduate mental health nursing students. Furthermore, the team recognized the usefulness of a 'realistic evaluation' appreach-(Pawson et 
al, 1997) in looking for 'general causal propositions' (Pawson \& Tilley, 1997 p. 122) in this case, possibly how and why the service user involvement was significant for learning.impact More specifically, the approach also drew from the work of Rush (2008) and using a 'realistic evaluation' approach (Pawson et al, 1997), cited Rush 2008) looking for 'general causal propositions' (Pawson \& Tilley, 1997 p. 122) for mechanisms and triggers, in this case how and why the service user involvement was positive for learning. Furthermore, the questions used by Rush (2008) were seen as useful given the responses offered therefore utilized for the group interviews.

For this work therefore, and-Ggiven the limits described previously and mindful of the above negotiated methodological approach, the team agreed for to upon collecting data from the written feedback forms (standard monitoring) and to also conduct two focus groups (group interviews) with the students involved ${ }_{2}=$

Kitzinger (1995) describes focus groups as a form of that is, -group interviews that benefitbenefitting from from the intergroup interaction and communications- (Kitzinger (1995) to yield a wide range of data $\div$ (Kitzinger (1995) with the facilitator (L) encouraging free discussion and responses with and to each other within the groups (Dahl et al, 2019). As O’Donnell et al (2013z) highlight focus groups are also "particularly useful for reflecting the social realities of a specific cultural group through direct access to the language and concepts that tend to organize participants' experiences" (O’Donnell et al, 2013z,p. 196)

Morgan (1996) broadly describes focus groups as a technique that collects data through group interactions on a topic determined by the researcher(s) albeit it is recognized that the strength of feelings or opinions are not commonly determined through focus groups alone (Basch, 1987).The team were aware that the focus groups would therefore-be large, more than is normally suggested, but were of the opinion that given the limited availability of both (L) and the students at the time, that to co-ordinate smaller facilitated groups would delay the evaluation and also possibly reduce participation as the students would not be available in the following weeks similar to the practicalities offered by Dahl et al (2019) and supported by Morgan (1997). - In addition, This method was chosen as it was viewed useful for exploring the students' experiences of learning from SUs extrapolating not only what their thoughts are, but how and why they think that (Kitzinger 1995) and also the stentsit was recognized that, as third year students, groups-they were familiar with each other and used to group-working_plus offering group 
feedback so arguably comfortable to speak freely.- Individual interviews were also-considered but viewed as overly time intensive for this undertaking within the restricted time available. 44 students participated in the unit, split into two groups for teaching purposes (limited room size availability), the focus groups conducted on the final teaching day for each group.

The team were aware that the focus groups were of a large size, more than is normally suggested, but were of the opinion that given the limited availability of both (L) and the stulents at the time, that to co-ordinate smaller facilitated groups would delay the evaluation and also possibly reduce participation as the students would not be in university in the following weeks.Individual interviews were also considered but viewed as overly time intensive for this undertaking within the restricted time available similar to the experience of Dahl et al (2019). Working with clinical midwives in an educational setting.

The gGroup interview_guide was_breally-adapted from Rush (2008) in and following an open, broad_systematic yet_conversational approach as suggested by (Patton (199220020, cited Rush 2008)._The SUs reviewed the questions and offered amendments eg. Adding Question 6.

The agreed main-questions were:

1) Can you broadly tell me about your experience of the service user sessions for this teaching unit-so far- e.g. good or bad?

2) Were the sessions as you expected?

3) How did learning from the service users differ from other methods such as lectures, seminars and reading?

4) You meet service users in your placements. Was the learning from them in the university setting different from learning from them in practice? - if so, how?

5) Will the service user input influence your practice at all?

6) Are there any other issues relating to service users being involved in your learning haven't been mentioned yet? 
44 students participated in the module, divided into two groups for teaching purposes, the two $1 \mathrm{hr}$ focus groups were conducted on the final teaching day for each group facilitated by L.

6)

There are many specific methodologies and philosophical approaches for qualitative research including, phenomenology, grounded theory and narrative inquiry. It was decided that a narrative appreach was the "best fit" as it would seek non numerical, relatively in depth data to explore (Hewitt Taylor 2011). This methodology was seen to fit the service evaluation as the team were seeking to capture the students' stories and accounts/experiences of learning with and from SUs, the resulting data to be interpreted, analysed and presented in relation to the whole experience (Elliot 2005, cited Hewitt Taylor 2011p. 68). In this context, their experience as student nurses learning from those they expect to provide care for and the subsequent embedded duality of their roles and the interesting juxtaposition of power.

\section{Ethical Approval}

Ethical approval was granted by the University Ethics Committee. The participant information sheets and consent forms were developed within the teaching team to ensure ease of understanding and were_amended as requested by the Ethics Committee to clarify the voluntary nature of participation and that the choice whether to do so or not would not impact on student their-progress on the programme. Following ethical approval, both cohorts $(n=44)$ were given the Participant Information Sheet (PIS) and Consent Forms prior to the beginning of unit delivery for consideration, they were also advised that they could withdraw consent at any time both on the forms plus before and after the focus groups.- - The teaching team had concluded that to reduce the possibility of role conflict for those involved and resulting perceived participant coercion that neither the LP, nor the three $\mathrm{SUs}_{2}$ - all of whom had the most contact with the students throughout the unit, including assessment involvement, would not conduct the focus groups, but that the $\mathrm{L}_{2}$ with the least unit input ${ }_{2}$ and the mestmore research experience would facilitate them andplus be the point of contact for comment/participation withdrawal. Confidentiality was assured and also that anonymity would be observed pertaining to dissemination of data as only 
the focus group facilitator (L) would be aware of the actual names of students and thus able to identify which student made a particular comment and this would not be shared with the wider unit team. The facilitator confirmed that data analysis would refer to the participants using codes only eg. ppPP 1, ppPP2 etc and also that they could withdraw consent at any time by contacting L as indicated on the PIS.

The choice of methodology/methods, although not without limits which this article does not have scope to explore, sought to enable effective and efficient data analysis to provide answers/insights into the original premise of the evaluation.

\section{Table 1 Summarises the Project Plan}

Table 1 Summary of Project Data Collection and Analysis Plan

\section{Development of Tools, Sampling and Process}

Reflecting upon the existing relevant literature, the team agreed that to complement the existing monitoring feedback and address the premise of the evaluation, the open questions for the focus groups were to be based upon the work of Rush (2008). They were as follows:

1. Can you tell me about your experience of the service user sessions in the classroom so far?

2. How does it differ from other methods such as lectures and reading material?

3. You meet service users every day in your practice learning experiences. In what way(s) does learning from them in the classroom differ from learning from them in practice?

4. Have the service user sessions influenced your practice at all?

As primarily qualitative enquiry was embraced for this work, non-probablility sampling was appropriate ie. All the third year students undertaking the unit. The sample for the evaluation-was purposive_-in that the cohorts_group selected were confirmed to be able to provide the rich, and possibly unique data for the matter issue the team were exploring what was being explored (Astin 2009) given that they had also experienced frequent service user input throughout their programme thus far, plus was convenient (Patton, 2002) as the participants would be easily accessible. $T$, they were also-convenient in terms of accessibility: plus inIn -facilitating the focus groups on the last taught_day of the unit, this was felt be more likely to draw responses 
based upon more immediate recall of their experiences and thus rely less on memory possibly providing more data .

Following ethical approval, both cohorts $(\mathrm{n}=44)$ were sent via email the Participant Information Sheet (PIS) and Consent Forms prior to the beginning of unit delivery, they were advised that their participation was voluntary, they could withdraw consent at any time and non-participation would not affect their progress on the programme. The cohorts were mixed in terms of gender (mainly female) average age 27yrs, and most with previous healthcare experience before undertaking the programme.

38 students took part in the focus groups, 6 in total from both cohorts were absent from the final teaching day and did not subsequently did not take part, their absence cited as unrelated to the planned focus groups.- All students further confirmed their consent verbally to participate on the day immediately prior to the focus groups beginning.

$\mathrm{L}$ conducted the $1 \mathrm{hr}$ focus groups at the end of the final day of the unit for both cohorts (separately) in the same teaching room as their sessions wereas delivered,, they lasted one hour. Further consent was obtained verbally before the groups began. Confidentiality was assured and also that anonymity would be observed pertaining to dissemination of data as only the focus group facilitator (L) would be aware of the actual names of students and thus able to identify which student made a particular comment and this would not be shared with the wider unit team. The facilitator confirmed that data analysis would refer to the participants using codes only eg. P1, P2 etc and also that they could withdraw consent at any time by contacting $L$ as indicated on the PIS.

Common practice when using interviews and focus groups is to audio and/or video record the groups, however time constraints (for transcription and confirmation) modified the process and $\mathrm{L}$ asked the questions and using the teaching screen available, typed the feedback directly on to a word document for the whole group to read so that all the participants were able to add/remove and confirm understanding concurrently. L also offered to speak with students privately, or receive further feedback via email should any student not wish to speak out in the group - no students took up this offer. 
On the day of the focus groups, L also recorded field notes immediately following the groups mindful of Kitzinger's (2005) suggestion that the facilitator in being present as a part of the focus groups experience can extrapolate further data through observation including the observed use of humour, consensus and dissent.

\section{Data Analysis}

The team were in agreement after a brief collaborative review of the data that one data analysis process would be appropriate. As an early career researcher, the author (L) choseused thematic analysis to explore the data from the two focus groups $(n=38)$ thus (Braun and Clark, 2006) in this case-capturing the experiences and realities of students' experiences, whilst mindful of the eomment "As there is no one way to conduct thematic analysis' (Braun and Clarke p.17). -(Braun and Clark, 2006). Given the lack of research expertise available at the time, tThe team agreed that thematic analysis would offer the-flexibility that being sought, rather than adopting a more specific (arguably more skilled) being wedded to-qualitative analysistic methods viewed that stem-from a particular theoretical or epistemological position eg. Grounded theory_(Braun and Clarke 2006). . Furthermore, aAs thematic analysis does not require the level of detail and technological knowledge of approaches (Braun and Clarke 2006) this allowed $L$ to analyse the data more confidently and in the short time available.Indeed, Basch et al (1987) confirms that the analysis of focus group data can be approached differently depending on the purpose of the $\underline{\text { study, orientation of the researcher(s) and limitations eg. Time, financial. Therefore, In this case }}$ thematic analysis was to be used as "a realist method to report experiences, meanings and the reality of participants" (Braun and Clarke 2006, p. 81). L therefore followed the-6 phases of thematic analysis as outlined by Bram and Clarke (2006), as indicated in Table 2.

E analysed the data from the two focus groups $(\mathrm{n}=38)$. . An inductive approach was used to identify themes, therefore they were-generated by the data and not using a pre-existing coding frame (Patton 199220020) plus clearly linked to the overall data set albeit the author/researcher was aware of the literature surrounding the topic. L shared the findings including codes and themes with the team for their review and thoughts through regular meetings and discussions, and also with some of the participants who had volunteered to review the findings. L also 


\section{Patterns and themes were noted during the verbal offered feedback and recorded by the researcher}

From the team $L$ analysed the data from the two focus groups $(n=38)$ and from the formal monitoring questionnaire feedback.

The team agreed with Gray's (2014) assertion that "one of the challenges of qualitative research is that there are no widely accepted rules about how qualitative data should be analysed, other than that the approach is generally deductive and involved the coding of data. "(Gray 2014, p. 602). Indeed, there are eritical arguments that could be seen as on a spectrum from 'storytelling' and description, little or no analysis (only presentation of data) to coding and categorising to formulate theoretical frameworks. Gray (2014) however suggests that data analysis should be a rigorous and logical process, progressing through description, disaggregating the data, making connections to provide a basis for fresh description (Gray 2014, p. 602) in this case, new insights as to the impact of SU input for student learning. The team shared this view.

The focus group was audio taped and transcribed verbatim. Asession summary sheet was also produced by the interviewer. Twomembers of the ALPS research team worked independently tocode the transcript. The researchers then met to compare emergingthemes and reflections from the two analyses. Themes were refinedand common definitions for the categories used agreed. Findingswere then sent to participants for member checking beforepublication From Muir and Laxton 2011...

Before data analysis $L$ and $L P$ agreed to consider reflexively their knowledge as actors within the evaluation, and the subsequent impact this may have on the iterative process of data analysis. They considered their broad knowledge of the literature surrounding service user input into 
mental health education, their experiential knowledge of working alongside the students as a group and individuals, and their own ontological and epistemological underpinning philosophies both for professional practice (nursing) as well as their pedagogical perspectives. Once articulated and identified, this provided a joint, yet individual approach and perspective to the data analysis whilst aware of potential biases as far as possible. This process also acknowledged the work of Fine (2002) who-suggests that researchers may, in fact, not just objectively "give woice" to the data, but selectively select and edit what is presented thus allowing their own voices to be heard also, knowingly or otherwise.

The team were in agreement after a brief collaborative review of the data from both sources (focus groups and questionnaire), that one data analysis process would be appropriate. They agreed that thematic analysis would offer the flexibility that was being sought, rather than being wedded to qualitative analytic methods that stem from a particular theoretical or epistemological position eg. Grounded theory, (Braun and Clarke 2006). As thematic analysis does not require the level of detail and technological knowledge of approaches (Braun and Clarke 2006) this allowed $L$ to analyse the data confidently and in the short time available. In this case thematic analysis was to be used as "a realist method to report experiences, meanings and the reality of participants" (Braun and Clarke 2006, p. 81). L followed the 6 phases of thematic analysis as outlined by Braun and Clarke (2006), as indicated in Table 2.

\section{Table 2. Thematic Analysis Process}

\section{Trustworthiness and Credibility}

Credibility was addressed through L confirming the feedback on an ongoing basis with participants as the focus groups took place and also through L sharing the findings anonymously with external academics (to the unit) and peer SUs-as peers. The data from the purposive sample was agreed as transferable when compared with the literature, and ${ }_{2}$ with dependability evident from the from the clear audit trail and-field notes/reflexive-diary/minutes recorded by $\mathrm{L}$ throughout the process. Also through the above, The reflexive processes during both unit delivery and analysis between L/LP/SU sought to address the ubiquitous issue of researcher bias and was reduced it as far as was deemed possible for this qualitative enquiry. as possible. 


\section{Summary of-Findings and Key Themes}

The final themes identified were agreed as relating to the overall evaluation question as to how and why service user involvement positively impacts on student nurse learning. The findings suggested that service user involvement was important for their learning and also offered insights into the power of the narrative, the educational impact and the practice impact. The SU sessions were all experienced positively by the students. In particularnoting particularlyOf note was that, the use of personal stories, crucially delivered in person $_{2}$ in real time (as opposed to an online/video resource), had the most power to facilitate learning.

When considering the power of the narrative as a strongly identified theme, L offered the phrase "Impact Testimony" in discussion frequently as it seemed to convey both the power of the story and the impact upon the students of that power for academic and professional practice.

\section{Power of the Narrative - "Impact Testimony".}

The students articulated that although their programme had an underpinning salutogenic approach in facilitating learning about health and social care for the profession embodied in

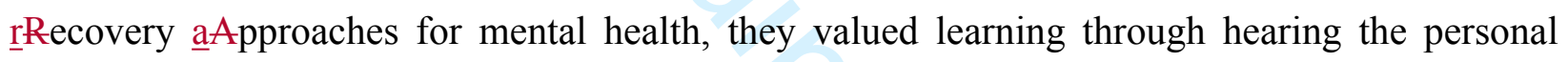
story from "a positive and well" SU. The students' feedback reflected their thoughts on both their role with clients currently as a student nurse ${ }_{2}$ and also as a registrant (qualified nurse). The 'personal' dimension was described as :

\footnotetext{
"hearing what it really feels like to be a client receiving the interventions that we do, it goes beyond what we are told that the evidence base states that clients think" (pp31)
}

"It's about the emotions, you hear and see their emotions when they talk, and, well, you feel it too, you can read about [clients'] feelings about things but it doesn't get you in the same way, you remember things better when you hear it like that" (pp27)

a) Wellness and Recovery

The students described "being taught" by the service user as a positive experience, as it

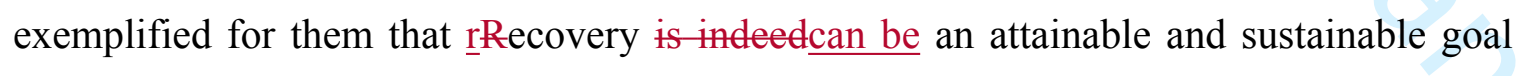
for clients and a provided a 'real world' evidence base for the care that they endeavour to provide. It moved the learning of theoretical approaches, recovery models and practical 
applications via interventions, beyond an academic undertaking as a student both in theory and practice, to a rationale that underpins their professional practice.

"Because we only know our clients when they are really ill, it's great to see recovery does actually work!” (pp22)

"Amazing to hear how even after all that, even thinking about suicide, he focussed on his assets and rebuilt his life" (pp1)

"It was just so positive to listen to his story, recovery really is an option" (pp33)

"We hear in theory [modules] mnits] the case studies of illness, refreshing to hear stories of wellness for a change!"(pp27)

b) The Recovery Journey and Humanistic Approaches.

Students articulated seeing their role in the care of a client as 'a small part' in the SU's Recovery Journey.

"It lets us see the bigger picture, the whole life picture...beyond just a care episode" (pp24)

Despite being a 'small part' in the SU journey the students described understanding the importance and meaning of a humanistic approach, clarified here as "understanding the little things mean a lot", the offering of tea/coffee, smiling, chatting, and offering time, speaking to, listening and supporting carers.

\footnotetext{
"You know, it's like these little things become part of the 'how to do' what we learn in theory, how do we normalise ...or even build a proper relationship to formulate for instance?" (pp4)
} 
"He reminded us that every interaction matters...about making the time to connect properly, not just do obs [observations]" (pp24)

"..hearing how even being given small choices can be a big deal....the start towards independence" (pp13)

"Listening made me think about why hope is so important - and not just for the client, we need to know and believe that recovery is possible, and let them know that we think that" (pp26)

"When I think of how often nurses are in the office with the door shut....hearing what that feels like...it makes the paperwork seem less, sort of, important somehow" (pp14)

c) Affirmation of Professional Role and 'Breaking Down the Barriers'

"...makes it less them and us" (pp34)

The students described understanding much more clearly the far reaching, often ongoing, impact that mental health stigma and (self) stigma can have on a client but they also articulated the sense that they also felt judged at times as a professional by clients and others. Also, as a professional, the students felt they were usually -'teaching the client' through interventions, and by being taught by the SUs and essentially 'swapping roles' this was perceived to further break down barriers. There was appreciation for the SUs taking time to teach them, as they felt this not only validated them as 'professionals-to-be' but as academic students. The students felt it positive "not to be seen as just staff", who have "power over the clients". This redressing of the perceived power imbalance was seen a positive step towards breaking down SU/Professional barriers, often cited in the literature and expressed negatively by professionals and SU alike. 
“...hearing him talk about being given his diagnosis, it became less 'just a diagnosis, label or whatever' to me, like we talk about all the time, - but a whole identity, a person" (pp18)

'Being judged and trusted works both ways....I hadn't thought about it until I realised how good I felt hearing about the staff that he valued and why......and how he understood where we were coming from and why we sometimes have to do what we do" (pp 27)

"I liked hearing the positive side of care, sometimes after a hard shift and all the things we sometimes to do to clients and how they react....you feel bad....it was good to hear that clients can see us beyond that, and that we did our best for them even though they were angry at the time" (pp14).

Students described appreciating the opportunity to ask relevant (deemed as seeking insight) questions of SUs during the sessions eg. care-delivery questions that they would like to ask of them when they are in a placement setting, but felt it would perhaps be inappropriate to do so.

"I am there to care for them....it wouldn't be right to ask, not that it doesn't matter what they think, just that, well, they are ill as well, other priorities...." (pp11)

\section{Educational Impact}

The students described learning from the SUs as different from 'being taught' (their words) by lecturers in the university.

a) Widened Breadth of Learning Students felt that there were possibly restrictions in how they "had to be taught by lecturers on the programme" which could perhaps limit their learning eg. Students commented that lecturers had to:

\footnotetext{
"Teach us by the book" (pp30)
}

"Say things the right way - in an academic way" (pp31) 
"Well I didn't want him to think I was stupid......he's marking our assignments after all...." (pp18)

The SU sessions were sometimes more interesting because of this aspect.

"We can ask all sorts of interesting questions, the stuff we would like to ask, but somehow don't feel it's appropriate in class" (pp15)

Questions in L/LP sessions were viewed as often assignment focussed and therefore narrow in their breadth, also the L/LP were described as being seen as 'assignment setters' as well as educationalists.

"We are usually thinking about what to put in the assignment, not just while we're listening, but thinking about what questions we want to ask" (pp29)

Students described feeling judged (negatively) in class at times by lecturing staffers - this was not the case with SUs which added to positive experience of learning as students felt more relaxed. There was felt to be expectations generally, and expectations of behaviour for both the lecturers and the students during the standard non SU sessions but this was not explored further other than being suggested as a limitation for learning. Despite the negative 
essence however, students were very clear that they would not wish to experience all their learning from SUs, they felt it important to be cognisant of the theory, research and evidence base as taught by academic or professional staff.

"Oh yeah but we couldn't do without that, we know we need it" (pp26)

\section{c) Integration of (Prior) Learning}

Students described the SU input as facilitating their learning through-integrating their prior learning, described as "making sense of what they are told". This was linked to decision making for practice and reflecting on the information learned earlier in the programme as . The example was given as follows. In year one, students were taught about boundaries across therapeutic relationships including the use of touch, usually to suggest instigating/maintaining boundaries generally and not touching clients, then in year 2 they learned about the therapeutic (considered) use of touch eg. For dementia clients, or those in great distress and physical interventions/restraint, then-in this, their final year,year 3 they are asked-expected to critically reflect upon their learning and demonstrate effective ethical clinical decision-making integrating many conflicting values and bodies of knowledge from the evidence base. The students outlined learning from the SU narratives as adding an additional, useful, dimension, as to what the experience of 'decision A, B or C' might actually be like for the SU in a given scenario. This was felt to usefully integrate their learning and therefore assist them in their clinical decisionmaking.

\section{Practice Impact}

The students described changing their practice as a result of the SU sessions.

a) Readjusting priorities

“I will change my practice....It's like a readjustment of priorities" (pp31)

The students outlined that by being in their $3^{\text {rd }}$ yearfinal year, they now lead and manage shifts and-or case-loads in practice, but they felt that when they listened to the SU narratives perhaps the priorities they previously held as key for their decision making were not always in the best interests of the client. A focus on risk-taking was highlighted, but often described as not 'positive risk-taking' for the benefit of client, but minimisationavoidance of risk in 
terms of liability for the professionat and organisation. The foeusemphasis on paperwork was also mooted as a behaviour-priority that currently occupied a great deal of the nurses' time (in an office) andpreventing-prevented them from being with the client, which the students felt they would now change for their practice.-

b) Evidence to Guide Practice

b) The students described the SU narratives as providing further evidence to guide practice for them.

"It makes the final link sort of, the link between evidence and practice....it's more meaningful when you hear it as it applied, you know, the interventions and what they feel like, how it works, the best way to do it, not just what we read or are told here [in theory]" (pp31)

In particular, the students articulated having a greater understanding of rRecovery as a concept, model and approach for practice and importantly 'how to' practice in a r Recovery focussed way. This drew on their understanding of thelinked to the personal narratives and the impact as to the human dimensions of care, "the little things" which also reflected the personal attitudes and attributes of the nurse eg. Ability to anticipate needs of clients and their carers, oeg. Offer support, time, and be genuine in expressions of empathy and understanding.-verbally and non - verbally. This was also linked byviewed as the students to delivering compassionate care, "seeing clients as humans....how we would want to be treated".

\section{"He reminded us that every interaction matters...about making the time to connect}

properly, not just do obs [observations] " (pp24)

c) Reaffirming the desire to be a mental health nurse 
Listening to the SU narratives also generated reflections as to why the students initially wanted to become mental health nurses thus reaffirming their wish to become qualified mental health nurses as they approached the end of their programme.

"Listening to his story reminded me that we can make a difference to someone's life and their family - that's what I wanted to do when I came in to the programme, to make a difference"(pp12)

"Hearing the hope and optimism for their future from them was so positive - nurses can, and do, help people we just don't always see it...or we forget amongst all the other stuff...’(pp6)

\section{StmmaryDiscussion}

The module-service evaluation generated evidence that not only further confirmed much of what can already be found in the literature with regard to the positiveconstructivepositive impact SUs have for learninghave upon learning. (Haeppell et al, 2014), but also offered further understanding as to 'how', and 'why', $\mathrm{SU}$ input into mental health education for students on healthcare programmes pesitively_impacts upon student learning so significantly, information about which-little of which can be found in the literature, which as Stacey and Pearson ((Petit-Zeman and Locock 2013, Stacey and Pearson 2018). highlight, there is a paucity of evidence as to mechanisms for this including the international literature (PetitZeman and Locock 2013).

which as Stacey and Pearson (2018) highlight, there is a paucity of evidence as to mechanisms for this including the international literature (Petit Zeman and Locock 2013). The SUs acknowledged from the dataThe findings confirm that as Rush (2008) suggests, it was not just theirthe SUs presence on the teaching days that impacted on learning but the use of their narratives, in part-to 'bring to life' what heystudents knew already from reading materials and traditional teaching modalities (Bollard et al 2012). Grant et al (2012), further 
suggest that, through narratives, students benefit from an enhanced understanding of the client experience, notwithstanding the critique that it can also be viewed as tokenistic often reflecting a power imbalance between professionals (clinical and academic) and service users (Epstein 2015) which although was not noted in this evaluation is an important consideration. To address the potential for the latter, the author suggestsperhaps HEIs would do well to should consider increasing co-production/-and-collaboration of healthwith national and international organisations for mental health and social care education, international co-production organisations, thus thus-following the lead fromfrom the -social work profession research and education-who encourage and supportembrace input from recognized SU organisations such as 'PowerUS' and 'Shaping Our Lives' for both -research and education as joint initiatives.-

The approach of the SUs, to include both receiving and asking questions of the students as part of the narrative, seemed to personalize hence deepen the learning, the emerging dialogue for learning perhaps similar to the conversational framework for learning as identified by (Laurillard, 2002):

Indeed, tIt also highlighted that this positive impact applied to both the general student experience at an HEI and also for the future workforce in terms of professional practice similar to the findings of Perrin (2014) who suggests that SU input offers 'real-world' insights into practice. The SU input seemed to touch the students personally and professionally and plus encourage deep critical reflection of both theory and practice_Rhodes 2013), and arguably could thus serve to reduce the ubiquitous concerns surrounding the Theory-Practice gap (Schon 1983, 1987) in nurse education as posited by White et al (date unknown) "Continual critical thinking and reflection can close the gap between theory and practice, improve quality of care and stimulate personal and professional development (Argyris \& Schön, 1978; Schon, 1983; Schon, 1987; Boud \& Walker, 1998; Epstein \& Hundert, 2002)" (White et al date unknown) and as confirmed by Happell , Bennetts, Platania Phung, \& Tohotoa,et al 2015.

From a pedagogical perspective, the work of Jack-Mezirow (1991) and his posited four stages forsurrounding transformative learning, suggests that the students, through engaging with the narratives, were perhaps able to 'experience' the story, thus critically reflect on their prior knowledge to embed or alter their knowledge plus use the opportunity to discuss and 
ask questions of the SU in order to 'action' this new understanding eg. Change their current practice as new skills emerge (Ranjan 1992, Tremayne et al, 2014). The new understanding emerging as the . as the-students were able to empathise and truly understand the experience of living with a mental health illness/distress (Byrne et al 2013, Bramley and Matiti 2014) as well as explore their own attitudes and those of their peer and colleagues with a view to changing and challenging negative stereotypes and practice (Byrne et al 2014, Happell et al 2014).-

Bocking et al (2019) as well as confirming that there is little in the evidence base to support the impact of SUs involvement in learning for students, suggestsoffers a further pedagogical perspective by way of explanation for the positive impact of the SU narratives, that-which focusses onhighlight the dialogues between SU and student, that of 'liberation or emancipatory education' based on the work of Friere (1970, cited Bocking et 2019, p.6). This approach suggests that the encouraged active involvement of the student assees learning and knowledge are-co-created with the SUs through the emerging questions and organic dialogue as opposed to the traditional didactic planned taught approach. Furthermore, Bocking et al (2019) also-echo theis findings of this study which highlight student recognition that those clients they work alongside in practice (recovery focussed) are not 'other' but the same as them - also with a life story to tell. , and also the importance for learning of being able to ask candid questions of the SUs whether of the services offered or stigma and the power of tabelling be that by others or the self (Stuart 2016).

In appreciating the recovery and salutogenic approach, the students were able to fully recognise the strengths and abilities that SUs had, seeing beyond their illness/diagnosis, similar to the findings of Simpson et al (2008). The students also recognised the role reversal in learning from SUs, in that they felt 'helped' to learn by the SUs as opposed to their traditional professional role of 'helper' when in the nursing role which also supported their understanding of the recovery approach and working alongside service users (Hanson and Mitchell, 2001) 
It should be noted that no contradictory data was yielded, ie. Student views suggesting that their experience was negative and/or of no learning value,. This was perhaps not surprising given that the students were accustomed to service user involvement within their teaching programme and therefore were not questioning the validity or expertise of the SU as mooted by Stacey and Pearson (2018). Furthermore, the SUs suggested it could be due to their familiarity with the students having worked with them throughout their programme and therefore reasserted that a different -research approach may elicit broader views.

\section{Limitations}

The findings from this exploratory module evaluation are limited to one final year group of mental health nursing students on one programme, in one $\mathrm{HEI}_{2}$ in the UK and focuses only on the student perspective. There is a need for a more robust, co-created (including all stakeholders), formal evaluation of SU input extending beyond one unit with perhaps a concurrent longitudinal research study given that SU input within this HEI for mental health education is inter-professional and frequently co-produced and co-delivered with SUs. Furthermore, the qualitative approach used in the conduct of this study is designed for detailed-exploration rather than generalization. Further research into the use of storytelling as an educational tool for mental health would be required before these views could be considered to reflect broader reviews

\footnotetext{
It should be noted that no contradictory data was yielded, ie. Student views suggesting that their experience was negative and/or of no learning value, a more formal mixed methods evaluation may have generated this wider data and is currently being considered. This was
} 
perhaps not surprising given that the students were accustomed to service user involvement within their teaching programme and therefore were not questioning the validity or expertise of the SU nor perhaps accepting of the clinician/medical model only dominance for 'expertise' as mooted by Stacey and Pearson (2018). Furthermore, the students given their experience of SU involvement, would be unlikely to view their imput as 'tokenism' only as suggested by Paul and Holt (2017) as a resistor to change, albeit for research involvement eould equally be applied to education.

a more formal mixed methods evaluation may have generated this wider data and is currently being considered. There is further also research to be explored as to the SU perspective and experience of sharing their narratives for learning and the impacts, potentially both positive and negative on the individuals involved..

The author suggests that the power of the narrative can be embodied within the term "Impact Testimony" by virtue of the impacts that the story, and indeed the storyteller themselves, can have upen his or her atdience.

\section{Conclusions}

This article seeks to addadds to the body of literature exploring the impact of SU input on learning, a requirement gap-highlighted by Scammell et al (2015) and Robinson and Webber (2013). Also, It also suggests that the use of focus groups/group interviews to bebeingwould be useful as part of standard formal teaching evaluations within the HEI (eg. as opposed to enline-surveys only) teaching/learning experience andplus to continue to develop and implement a range of innovative pedagogical approaches for learning co-created with SUs. In particular this paper echoes and endorses the use of skilled narrative/storytelling as a pedagogical approach encouraging learning through dialogue and participation with students. Key to the success of this is the inclusion of SUs in the co-production and delivery of the teaching and a shared philosophical approach. This inclusion could be enhanced and strengthened through inviting integrated organisations (eg. Shaping Our Lives) to meaningfully participate in curricula development, and-delivery and evaluation or, alternatively for the UK, consider formally collaborating with Recovery Colleges (Askheim et al, 2017, DOH 2011)-. These organisations 
which-promote collaboration and co-production between peopleindividuals with personal and professional experience of mental health challenges for education particularly surrounding mental health and recovery therefore tocould potentially co- deliver mental health courses/education for healthcare programmes supporting recovery with a focus on an individual's strengths-(McGregor et al., 2014)..-

The findings from the above service-module evaluation generated much reflection and discussion within the teaching team. The LP, L, and SUs involved agreed that there was now the rationale and scope to increase the significant meaningful personal-involvement of SUs not just within this unit/programme, but as fundamental within the programme, and but also potentially the other healthcare programmes at the HEI using these identified live 'impact testimonies' as a principal dimension, with theoretical perspectives and evidence-based practice supporting the narratives thus offering students unique, and potentially transformative learning opportunities. The latter supported by - Church (2012), cited Beresford 2014) who highlights the importance of SU personal narratives for mental health education and learning/teaching alongside traditional formal knowledge transfer. Taking this argument furtherIn addition, it would seem timely to reconsider the permanent appointment of SUs to HEIs inas a-substantive academic role $\bar{y}$, as well as ensuring their significant input into curricula development, -actions, as Bocking et al (2019) suggests, yet that remain slow to embed within the education sector, an issue highlighted already by Levin (2004) despite funding available. Perhaps more can follow the lead of UK social work education which has successfully seen the appointment of service users to professorial level eg. Professor Peter Beresford OBE, thus both research and education truly led and informed by service users (Benjamin, 2019). - as well as having ensuring significant input into curricula development (Happellet a1, 2019).

In particular this paper echoes and endorses the use of skilled narrative/storytelling as at pedagogical approach encouraging learning through dialogue and participation with students, from active listening to asking questions. Key to the success of this is the inclusion of SUs in 
the co-production and delivery of the teaching and a shared philosophical approach .mindfut of shared expertise.

The use of focus groups as part of regular teaching evaluation would seem appropriate to generate further data to enhance the teaching/learning experience and to develop and implement a range of pedagogical approaches for learning

Finally, the author suggests that the power of the narrative can be embodied within the term "Impact Testimony" by virtue of the impacts that the story, and indeed the storyteller $\underline{\text { themselves, can have upon his or her audience. }}$

\section{References}

Arblaster, K., Mackenzie, L. \& Willis, K. (2015). Mental health consumer participation in education: a structured literature review. Australian Occupational Therapy Journal, 62 (5), 341362.

Askheim, O.P., Beresford, P. and Heule, C., 2017. Mend the gap-strategies for user involvement in social work education. Social Work Education, 36(2), pp.128-140-

Astin., F., 2009 A Beginner's Guide to Appraising a Qualitative Research Paper. British Journal of Cardiac Nursing, 4,11: 530-3

Basch, C. E. (1987) 'Focus Group Interview: An Underutilized Research Technique for Improving Theory and Practice in Health Education', Health Education Quarterly, 14(4), pp. $\underline{411-448 .}$

Bazeley., P., 2004 .Issues in Mixing Qualitative and Quantitative Approaches to Research Published in: R. Buber, J. Gadner, \& L. Richards (eds) (2004) Applying qualitative methods to marketing management research. UK: Palgrave Macmillan, pp141-156. 
Braun., V., Clarke., V. 2006.Using Thematic Analysis in Psychology. Qualitative Research In Psychology. 2006. 3:77-101

Byrne, L., Happell, B., Welch, T. \& Moxham, L. (2013). 'Things you can't learn from books': teaching recovery from a lived experience perspective. International Journal -of Mental Health Nursing, 22, 195-204.

Byrne, L., Platania-Phung, C., Happell, B., Harris, S. \& Bradshaw, J. (2014). Changing nursing student attitudes to consumer participation in mental health services: a survey study of traditional and lived experience-led education. Issues in Mental Health Nursing, 35, 704-712. 
Carter, S., M., and Little, M., 2007. Justifying Knowledge, Justifying Method, Taking Action: Epistomologies, Methodologies, and Methods in Qualitative Examples of Frameworks, Qualitative Health Research, 17,10: 1316-28

Cobley, P. (2001) Narrative. London: Routledge.

Dahl, B., Røseth, I., Lyberg, A., Bongaardt, R. and Sommerseth, E., 2019. Education is a private matter: Clinical midwives' experiences of being part-time master's students in midwifery. Nurse education in practice, 39 , pp.32-36.

Department of Health, 2006. From values to action: The Chief Nursing Officer's review of mental health nursing.

Department of Health (2011), No Health Without Mental Health: a Cross Governmental Mental Health Outcomes Strategy for People of all Ages, HM Government, London

Department of Health 2012 Compassion in Practice: Nursing, Midwifery and Care Staff, our Vision and Strategy.

Epstein, M. 2015. Pluck, Acceptance, Defiance And Fortitude: Telling Mental Illness Stories To Change The World. Melbourne: My Consumer Place

Francis, R., 2013. Report of the Mid Staffordshire NHS Foundation Trust public inquiry: executive summary (Vol. 947). The Stationery Office.

Gray., D. 2014. Doing Research in the Real World. $3^{\text {rd }}$ Ed. London. Sage.

Grant, A., Biley, F. C., Leigh-Phippard, H. \& Walker, H. 2012. The book, the stories, the people: an ongoing dialogic narrative inquiry study combining a practice development project. Part 1: the research context. Journal of Psychiatric and Mental Health Nursing, 19, 844-851.

Health and Care Professions Council (HCPC), 2013. Standards for education and training programmes. Service user and carer involvement in education and training programmes.

Hanson, B., \& Mitchell, D.M. (2001). Involving mental health service users in the classroom: A course of preparation. Nurse Education in Practice, 1, 120-126.

Happell, B., Platania-Phung, C., Scholz, B., Bocking, J., Horgan, A., Manning, F., Doody, R., Hals, E., Granerud, A., Lahti, M. and Pullo, J., 2019. Changing attitudes: The impact of Expert 
by Experience involvement in Mental Health Nursing Education: An international survey study. International journal of mental health nursing, 28(2), pp.480-491.

Happell, B., Platania-Phung, C., Byrne, L., Wynaden, D., Martin, G. \& Harris, S. (2015). Consumer participation in nurse education: a national survey of Australian universities. International Journal of Mental Health Nursing, 24, 95-103.

Happell, B., Bennetts, W., Platania-Phung, C., \& Tohotoa, J. (2015.). Consumer involvement in mental health education for health professionals: Feasibility and support for the role. Journal of Clinical Nursing, 24(23-24)

Happell, B., Byrne, L., McAllister, M. et al. (2014). Consumer involvement in the tertiary-level education of mental health professionals: a systematic review. International Journal of Mental Health Nursing, 23 (1), 3-16.

Happell, B. and Bennetts, W., 2016. Triumph and adversity: Exploring the complexities of consumer storytelling in mental health nursing education. International journal of mental health nursing, 25(6), pp.546-553.

Happell, B., Wilson, K., Platania-Phung, C. and Stanton, R., 2017. Physical health and mental illness: listening to the voice of carers. Journal of Mental Health, 26(2), pp.127-133.

Horgan, A., Manning, F., Bocking, J., Happell, B., Lahti, M., Doody, R., Griffin, M., Bradley, S.K., Russell, S., Bjornsson, E. and O'Donovan, M., 2018. 'To be treated as a human': Using co-production to explore experts by experience involvement in mental health nursing educationThe COMMUNE project. International journal of mental health nursing, 27(4), pp.1282-1291

Hewitt-Taylor, J., 2011. Using Research in Practice: it sounds good, but will it work? Basingstoke: Palgrave Macmillan.

Holloway., I, Freshwater., D., 2007. Vulnerable story telling: narrative research in nursing. Journal of Research in Nursing 2007 12: 703

Kitzinger, J., 1994. The methodology of focus groups: the importance of interaction between research participants. Sociology of health \& illness, 16(1), pp.103-121.

Kitzinger., J, 1995. Qualitative research. Introducing focus group British Medical Journal 1995 Jul 29;311(7000):299-302.

Kitzinger, J. 2005 Focus Group Research: Using Group Dynamics to Explore Perceptions, Experiences and Understandings. In: Holloway, I., Ed., Qualitative Research in Health Care, Open University Press, Maidenhead, 56-70. 
Kuti, B. and Houghton, T., 2019. Service user involvement in teaching and learning: student nurse perspectives. Journal of Research in Nursing, 24(3-4), pp.183-194.

Lee., P., 2006. Understanding and Critiquing Qualitative Research Papers. Nursing Times, 102 , $29: 30-2$

Laurillard, D., 2002. Rethinking University Education: A conversational framework for the effective use of learning technologies. RoutledgeFalmer, London.

Levin, E. 2004. Involving Service Users and Carers in Social Work Education Resource Guide No 2, Social Care Institute for Excellence, London

Malterud, K., 2001. Qualitative research: standards, challenges, and guidelines. The lancet, 358(9280), pp.483-488.

McGregor, J. , Repper, J. and Brown, H. (2014), "The College is so different from anything I have done'. A study of the characteristics of Nottingham Recovery College", Journal of Mental Health Education Training and Practice, Vol. 9 No. 1, pp. 3-15.

Mezirow, J., 1991. Transformative dimensions of adult learning. Jossey-Bass, 350 Sansome Street, San Francisco, CA 94104-1310.

Morgan, D.L. and Morgan, D., 1997. Focus Groups as Qualitative Research (Vol. 16). SAGE.

Morgan, D.L., 1996. Focus groups as qualitative research (Vol. 16). Sage publications.

Morse JM, ed. Qualitative health research. Newbury Park, CA: Sage Publications; 1992.

Morse, J.,M. 2012. Qualitative Health Research: Creating a New Discipline. Routledge Walnut Creek, California..

Muir, D. and Laxton, J.C., 2012. Experts by experience; the views of service user educators providing feedback on medical students' work based assessments. Nurse education today, 32(2), pp.146-150.

NHS England .2015. Five year forward view. London, UK: HMSO

NHS 2012. NHS constitution. London, UK: HMSO.

Nursing and Midwifery Council. 2010. Standards for pre-registration nursing. London, UK:

NMC. 
O'Donnell, H. and Gormley, K., 2013. Service user involvement in nurse education: perceptions of mental health nursing students. Journal of Psychiatric and Mental Health Nursing, 20(3), pp.193-202.

Patton.,M.Q. 2002., Qualitative Research \& Evaluation Methods (third ed.), Sage Publications, Thousand Oaks, CA (2002)Patton, M.Q. 1990. Qualitative evaluation and research methods (2nded.). Newbury Park, CA: Sage.

Pawson, R., \& Tilley, N. (1997). Realistic evaluation. London: Sage Publications

Petit-Zeman, S. and Locock, L., 2013. Health care: bring on the evidence. Nature News, 501(7466), p.160.

Perry, J., Watkins, M., Gilbert, A. and Rawlinson, J., 2013. A systematic review of the evidence on service user involvement in interpersonal skills training of mental health students. Journal of psychiatric and mental health nursing, 20(6), pp.525-540.

PowerUS (International) An International Network of Teachers and Researchers from Schools of $\underline{\text { Social Work and Representatives from Service User Organizations }}$ https://powerus.eu/ [Accessed 21/10/19]

Ranjan _(-1992. - -Silent learning: Experience as a way of knowledge. In: Mulligan J and Griffin C (eds) Empowerment Through Experiential Learning: Explorations of Good Practice. London: Kogan Page Limited, pp. 76-81.

Rhodes, C. A. (2012). User Involvement in health and social care education: A concept analysis. Nurse Education Today, 32, 185-189.

Rhodes, C., 2013 Service user involvement n pre-registration children's nursing education: the impact and influence on practice: a case study on the student perspective. Issues in Comprehensive Pediatric Nursing 36, 291-308.

Ranjan (1992) Silent learning: Experience as a way of knowledge. In: Mulligan J and Griffin C (eds) Empowerment Through Experiential Learning: Explorations of Good Practice. London: Kogan Page Limited, pp. $76-81$.

Rush., B., 2008. Mental health service user involvement in nurse education: A catalyst for transformative learning. Journal of Mental Health. October 2008. 17 (5): 531-542. 
Mezirow, J. (1991). Transformative dimensions of adult learning. San Francisco: Jossey Bass

Russell., C., K., and Gregory., D., M., 2003. Evaluation of Qualitative Research Studies.

Evidence Based Nursing, 6,2:36-40

Robinson, K. and Webber, M., 2012. Models and effectiveness of service user and carer involvement in social work education: A literature review. British Journal of Social Work, 43(5), pp.925-944.

Scammell, J., Heaslip, V. and Crowley, E., 2016. Service user involvement in preregistration general nurse education: a systematic review. Journal of Clinical Nursing, 25(1-2), pp.53-69.

Z. Schneider, D. Whitehead, G. Lobiondo-Wood, J. Haber., 2013 Nursing and Midwifery Research: Methods and Appraisal for Evidence-Based Practice (fourth ed.), Elsevier Australia, Chatswood, New South Wales (2013

Schon D.A. 1983. The reflective practitioner: How professionals think in action. New York: Basic Books.

Schon D.A. 1987. Educating the reflective practitioner: Toward a new design for teaching and learning in the professions. San Fransisco, CA: Jossey-Bass Inc.

Shaping Our Lives (UK) A National Network of Service Users and Disabled People https://www.shapingourlives.org.uk/ [Accessed 17/10/19]

Simpson, A., Reynolds, L., Light, I. and Attenborough, J., 2008. Talking with the experts: Evaluation of an online discussion forum involving mental health service users in the education of mental health nursing students. Nurse education today, 28(5), pp.633-640.

Stacey, G. \& Pearson, M. (2018). Exploring the influence of feedback given by people with lived experience of mental distress on learning for pre-registration mental health students. Journal of Psychiatric and Mental Health Nursing, 25, 5-6.

Schon D.A. 1983. The reflective practitioner: How professionals think in action. New York: Basic Books.

Schon D.A. 1987. Educating the reflective practitioner: Toward a new design for teaching and tearning in the professions. San Fransiseo, CA: Jossey-Bass Inc. 
Stebbens, R., 2001. Exploratory research in the social sciences: (Qualitative research methods).

Stewart, D.W. and Shamdasani, P.N., 2014. Focus groups: Theory and practice (Vol. 20). Sage publications.Stewart D.W. \& Shamdasani P.N. 1990. Focus Groups: Theory and Practice. Sage, London

Stuart, H. (2016). Reducing the stigma of mental illness. Global Mental Health, 3, 9-11.

Tobbell, J., Boduszek, D., Kola-Palmer, S., Vaughan, J. and Hargreaves, J., 2018. Evaluating service user pedagegy in UK higher education: Validating the Huddersfield Service User Pedagogy Seale. Nurse edution tody, 63, pp.81 86.

Tremayne P, Russell P and Allman H .(2014. - -Service user involvement in nurse education. Nursing Standard 28(22): 37-41.

White., P, Laxton., J., Brooke., R., (unknown date) Reflection: Importance, Theory and Action. Unpublished Paper. http://www.alpscetl.ac.uk/documents/Reflection_BAA_article_submission.pdf [Accessed 10/10/2018]

Table 2. Thematic Analysis Process

Table 1 Summary of Project Data Collection and Analysis Plan

\begin{tabular}{|c|c|c|}
\hline Data Source & $\begin{array}{l}\text { Method of Data Collection/Team } \\
\text { Member Lead }\end{array}$ & $\begin{array}{l}\text { Method of Analysis/Team } \\
\text { Member Lead }\end{array}$ \\
\hline $\begin{array}{l}443^{\text {rd }} \text { Yr. } \\
\text { Undergraduate } \\
\text { Student Nurses } \\
\text { undertaking the } \\
\text { unit. } \\
20 \text { and } 24 \text { in } \\
\text { each cohort } \\
\text { being taught } \\
\text { concurrently, } \\
\text { therefore } 2\end{array}$ & $\begin{array}{l}2 \text { Focus Groups ( } 1 \mathrm{hr} \text { each), one_with each } \\
\text { cohort - to be conducted on the last day of } \\
\text { unit delivery. } \\
\text { Field notes to be taken at the time and at } \\
\text { the end of the focus groups. Reflexive } \\
\text { diary kept } \\
\text { Collate Standard Formal Monitoring } \\
\text { Written Feedback made available during } \\
\text { the unit delivery }\end{array}$ & $\begin{array}{l}\text { Thematic analysis of feedback, } \\
\text { ensuring team collaboration and } \\
\text { input plus record/minute taking } \\
\text { of all meetings and discussions } \\
\text { particularly analysis related. } \\
\text { (L)- }\end{array}$ \\
\hline
\end{tabular}


\begin{tabular}{l|l} 
cohorts. & $(\mathrm{L})$ \\
\hline
\end{tabular}

Table 2. Thematic Analysis Process

\begin{tabular}{|c|c|c|}
\hline & Phase & Action \\
\hline 1 & Familiarising yourself with the data & $\begin{array}{l}\text { The verbal data offered by the students in the focus } \\
\text { groups/group interviews to L - the written feedback } \\
\text { from the students was interpretative but checked } \\
\text { with the students at the time, 'meanings' were } \\
\text { created and checked at the time to ensure } \\
\text { punctuation and emphasis for 'correct 'meaning of } \\
\text { the spoken words. } \\
\text { L read, and re-read the offered full feedback looking } \\
\text { for initial themes and patterns. A list was made of } \\
\text { ideas of what is in the data and what was thought to } \\
\text { be of note. Ideas for coding were noted, albeit linked } \\
\text { to the literature/what was previously known on the } \\
\text { topic as it was difficult to 'unknow' the literature. } \\
\text { L also reviewed the field notes made for the focus } \\
\text { groups (observations and reflections) at the time. } \\
\text { The potential themes, patterns and codes were } \\
\text { discussed with the team for consensus and shared } \\
\text { insights. These discussions were written down to } \\
\text { maintain a timely record of team thoughts and } \\
\text { reflections. } \\
\text { Team reading and re-reading the written } \\
\text { questionnaire data and focus group data, making } \\
\text { notes then sharing initial ideas. }\end{array}$ \\
\hline 2 & Generating initial codes & $\begin{array}{l}\text { Once the ideas about the data had been discussed } \\
\text { and agreed within the team, the elements (line by } \\
\text { line text) in the raw data were grouped together, to }\end{array}$ \\
\hline
\end{tabular}


(Modified from Braun and Clarke 2006, p. 87) 
Table 1 Summary of Project Data Collection and Analysis Plan

\begin{tabular}{|c|c|c|}
\hline Data Source & $\begin{array}{l}\text { Method of Data Collection/Team } \\
\text { Member Lead }\end{array}$ & $\begin{array}{l}\text { Method of Analysis/Team } \\
\text { Member Lead }\end{array}$ \\
\hline $\begin{array}{l}443^{\text {rd }} \text { Yr. } \\
\text { Undergraduate } \\
\text { Student Nurses } \\
\text { undertaking the } \\
\text { unit. } \\
20 \text { and } 24 \text { in } \\
\text { each cohort } \\
\text { being taught } \\
\text { concurrently, } \\
\text { therefore } 2 \\
\text { cohorts. }\end{array}$ & $\begin{array}{l}2 \text { Focus Groups ( } 1 \mathrm{hr} \text { each), one with each } \\
\text { cohort - to be conducted on the last day of } \\
\text { unit delivery. } \\
\text { Field notes to be taken at the time and at } \\
\text { the end of the focus groups. } \\
\text { (L) }\end{array}$ & $\begin{array}{l}\text { Thematic analysis of feedback, } \\
\text { ensuring team collaboration and } \\
\text { input plus record/minute taking } \\
\text { of all meetings and discussions } \\
\text { particularly analysis related. } \\
\text { (L) }\end{array}$ \\
\hline
\end{tabular}

Table 2. Thematic Analysis Process

\begin{tabular}{|l|l|l|}
\hline 1 & Phase & Action \\
\hline 1 & Familiarising yourself with the data & $\begin{array}{l}\text { The verbal data offered by the students in the focus } \\
\text { groups/group interviews to L - the written feedback } \\
\text { from the students was interpretative but checked } \\
\text { with the students at the time, 'meanings' were } \\
\text { created and checked at the time to ensure } \\
\text { punctuation and emphasis for 'correct 'meaning of } \\
\text { the spoken words. }\end{array}$ \\
$\begin{array}{l}\text { L read, and re-read the offered feedback looking for } \\
\text { initial themes and patterns. A list was made of ideas } \\
\text { of what is in the data and what was thought to be of } \\
\text { note. Ideas for coding were noted, albeit linked to } \\
\text { the literature/what was previously known on the } \\
\text { topic as it was difficult to 'unknow' the literature. }\end{array}$ \\
L also reviewed the field notes made for the focus
\end{tabular}




\begin{tabular}{|l|l|l|}
\hline & (team) & biases. \\
\hline 7 & Producing the report & $\begin{array}{l}\text { L produced the final summary selecting key } \\
\text { extracts/examples reflecting the analysis and relating } \\
\text { back to the original premise of the evaluation and } \\
\text { literature. }\end{array}$ \\
\hline
\end{tabular}

(Modified from Braun and Clarke 2006, p. 87)

Table 3 - Summary of Codes and Themes

\begin{tabular}{|l|l|}
\hline Codes & Themes \\
\hline Wellness and recovery & 1 Power of the Narrative - "Impact Testimony". \\
\hline $\begin{array}{l}\text { The recovery journey and humanistic } \\
\text { approaches }\end{array}$ & \\
\hline $\begin{array}{l}\text { Affirmation of professional role and } \\
\text { 'Breaking Down the Barriers' }\end{array}$ & \\
\hline & 2. Educational Impact \\
\hline Widened breadth of learning & \\
\hline Role of the Lecturer/LP/Professional Staff & \\
\hline Integration of (Prior) Learning & 3. Practice Impact \\
\hline & \\
\hline Readjusting priorities & \\
\hline Evidence to guide practice & \\
\hline $\begin{array}{l}\text { Reaffirming the desire to be a mental health } \\
\text { nurse }\end{array}$ & \\
\hline
\end{tabular}

